Percutaneous endoscopic gastrostomy (PEG) is frequently performed in patients suffering from head and neck carcinoma to provide adequate nutrition after radiation therapy. Metastases of the original tumor at the cutaneous exit of the gastrostomy may occur, but have rarely been described up to now [1].

A 75-year-old woman who suffered from a T4N0M0 hypopharyngeal carcinoma underwent gastroscopy for PEG placement after primary diagnosis was made. A stenotic polypoid tumor was seen in the pharynx, which was soft. Passage with the gastroscope was easily performed. A 12 Charr. PEG was placed using the "pull" technique. Subsequent to PEG implantation the patient received radiation therapy. At 15 weeks later, she developed an elevated, painless granulomatous lesion at the cutaneous exit of the PEG (Figure 1). There were no clinical signs of inflammation. With histological examination, a metastasis of a squamous cell car-

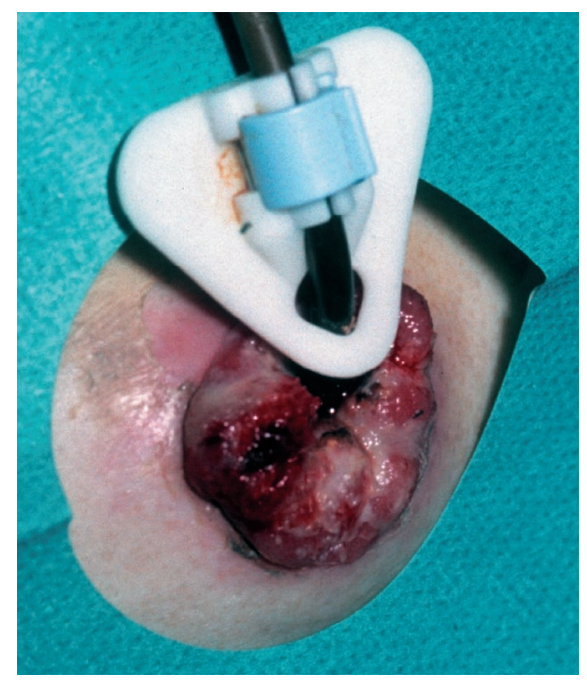

Figure 1 Granulomatous lesion at the exit site of the gastrostomy tube, 4 months after percutaneous endoscopic gastrostomy (PEG) placement.

\title{
Implantation Metastasis of a Hypopharyngeal Carcinoma at the Site of a Percutaneous Endoscopic Gastrostomy
}

cinoma was found, which derived from the hypopharyngeal carcinoma (Figure 2 ).

In the present case, as in 19 previously reported cases of implantation metastases at PEG exit sites [1], PEG was performed using the "pull" technique. No technical problems occurred during PEG insertion. The retention plate passed the tumor easily, without consecutive tumor bleeding or destruction of the tumor.

As seeding of tumor cells in the abdominal wall appears likely to be caused by transfer of the inner retention plate, it should be discussed whether placement of the gastrostomy tube using the "push" method [2] should be proposed, to minimize direct contact with oropharyngeal tumors. In our own experience, a modification of the "push" technique, performing PEG with gastropexy in the absence of a retention plate [3], could be a practicable alternative in cases of polypoid head and neck tumors.

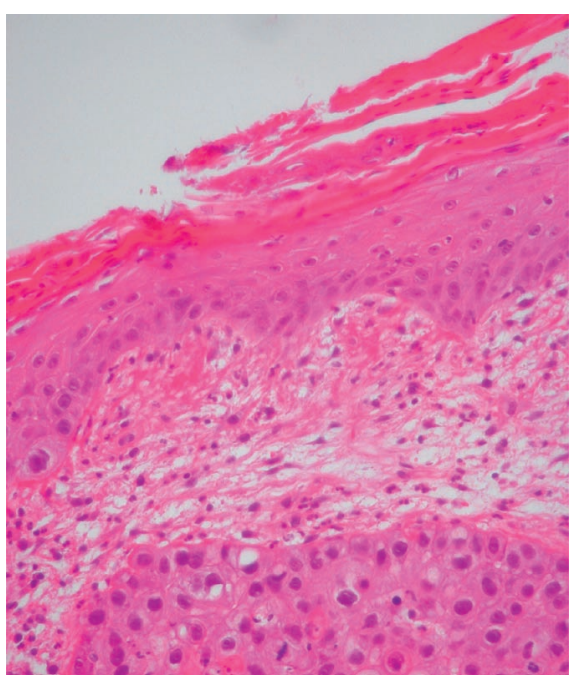

Figure 2 Histological specimen from the percutaneous endoscopic gastrostomy (PEG) exit site, demonstrating a cutaneous metastasis of a squamous cell carcinoma.
R. Kurdow ${ }^{1}$, B. Schniewind ${ }^{1}$, Y. Delere ${ }^{1}$, A.-S. Boehle ${ }^{1}$, J. Lüttges ${ }^{2}$, J. M. Doniec ${ }^{1}$

${ }^{1}$ Clinic for General Surgery and Thoracic Surgery, University Hospital, Christian Albrechts University, Kiel, Germany

${ }^{2}$ Department of Pathology, University Hospital, Christian Albrechts University, Kiel, Germany

\section{References}

${ }^{1}$ Sinclair JJ, Scolapio JS, Stark ME et al. Metastasis of head and neck carcinoma to the site of percutancous endoscopic gastrostomy: case report and literature review. J Parenter Enteral Nutr 2001; 25: $282-285$

${ }^{2}$ Hogan RB, DeMareo DC, Hamilton JK et al. Percutaneous endoscopic gastrostomy - to push or pull. A prospective randomized trial. Gastrointest Endosc 1986; 32: $253-258$

${ }^{3}$ Dormann AJ, Glosemeyer R, Leistner U et al. Modified percutaneous endoscopic gastrostomy (PEG) with gastropexy - early experience with a new introducer technique. Z Gastroenterol 2000; 38: 933 -938

\section{Corresponding Author}

\section{R. Kurdow, M.D.}

Dept. of General and Thoracic Surgery University Hospital Christian-Albrechts-University Amold-Heller-Str. 7 24105 Kiel Germany

Fax: $\quad$ +49-431-5974586

E-mail: rkurdow@surgery.uni-kiel.de 